\title{
Rectal Cancer
}

\author{
James W. Fleshman, MD, FACS, FASCRS ${ }^{1}$ Warren E. Lichliter, MD, FACS, FASCRS ${ }^{1}$ \\ ${ }^{1}$ Department of Surgery, Baylor University Medical Center, Dallas,
}

Texas

Clin Colon Rectal Surg 2015;28:3-4.

The treatment of rectal cancer has changed significantly over the last century and even in the last decade. The theme of this issue of the Clinics is an update of the most critical changes that are affecting the way we as colon and rectal surgeons manage patients with the many different specific issues that rectal cancer brings to patient care. We have gathered individuals who are focused on the current therapy of patients with rectal cancer to deal with several particularly controversial issues, present state of the art, and changes in management. The use of varying types of surgical modalities to accomplish the correct surgical procedure, methods to achieve complete resection of early and advanced tumors, multidisciplinary discussion and management of rectal can- cer patients throughout their course, appropriate staging and molecular evaluation of the pathologic specimen, and perioperative management and reduction of complications are all presented. This issue provides insight into some of the details of these changes and controversies to help the practicing colon and rectal surgeon adjust. We want to thank the contributors for their excellent contributions and Dr. David Beck for allowing us to present this information.

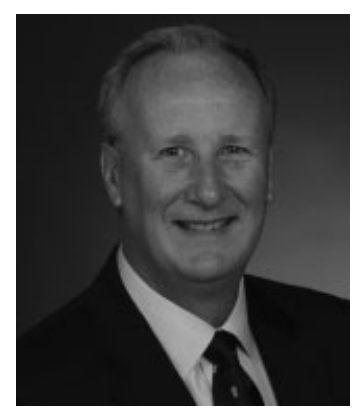

James W. Fleshman, MD, FACS, FASCRS

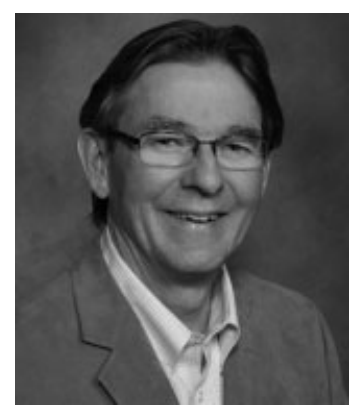

Warren E. Lichliter, MD, FACS, FASCRS
Address for correspondence James W. Fleshman, MD, FACS, FASCRS, Department of Surgery, Baylor University Medical Center, 3501 Junius St, Dallas, TX 75246 (e-mail: James.

Fleshman@baylorhealth.edu).
Issue Theme Rectal Cancer; Guest Editors: James W.

Fleshman, MD, FACS, FASCRS, and Warren E. Lichliter, MD, FACS, FASCRS
Copyright (c) 2015 by Thieme Medical Publishers, Inc., 333 Seventh Avenue, New York, NY 10001, USA. Tel: +1(212) 584-4662.
DOI http://dx.doi.org/ 10.1055/s-0035-1545063. ISSN 1531-0043. 